\title{
HIF-1 $\alpha$ Plays a Role in the Chemotactic Migration of Hepatocarcinoma Cells Through the Modulation of CXCL6 Expression
}

\author{
Hui Tian ${ }^{\mathrm{a}}$ Peixin Huang ${ }^{\mathrm{a}}$ Zhiying Zhao ${ }^{\mathrm{a}}$ Wenqing Tanga Jinglin Xia ${ }^{\mathrm{a}, \mathrm{b}}$ \\ aLiver Cancer Institute, Zhongshan Hospital, Fudan University; Key Laboratory of Carcinogenesis and

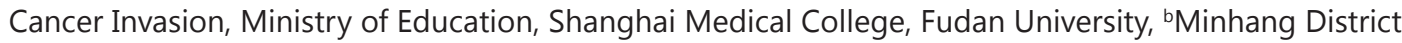 \\ Central Hospital, Shanghai, China
}

\section{Key Words}

Hepatocellular carcinoma $\cdot$ HIF- $1 \alpha \cdot$ CXCL6 $\bullet$ Metastasis

\begin{abstract}
Background/Aims: Hypoxia promotes the progression and metastasis of hepatocellular carcinoma (HCC). Hypoxia inducible factor- $\alpha$ (HIF-1 $\alpha$ ) regulates the expression of various chemokines involved in tumor growth, angiogenesis and metastasis. Methods: The role of HIF-1 $\alpha$ in HCC tumor growth and invasion and the prognosis of patients with HCC was investigated in cell lines and patient samples. HIF-1 $\alpha$ mRNA and protein levels were assessed by qRT-PCR and western blotting. Silencing of HIF-1 $\alpha$ downregulated the expression of granulocyte chemotactic protein-2 (GCP-2)/CXCL6, a CXC ELR+ chemokine, in HCC cells, and a luciferase assay showed that HIF-1 $\alpha$ binds to a hypoxia response element in the promoter of CXCL6 and regulates its transcription. Induction of HIF- $1 \alpha$ by hypoxia promoted the migration and invasion of HCC cells in vitro, and this effect was suppressed by an anti-CXCL6 antibody. Results: HIF-1 $\alpha$ is upregulated in HCC cell lines and tissues and its effect on promoting invasion and metastasis is mediated by its direct interaction with the pro-angiogenic chemokine CXCL6. CXCL6 expression was associated with poor prognosis of HCC patients. Conclusion: HIF-1 $\alpha$ promotes HCC progression and metastasis by upregulating CXCL6 transcription in HCC cells, providing a potential novel therapeutic target for the treatment of HCC.
\end{abstract}

H. Tian, P. Huang and Z. Zhao contributed equally to this work.

Prof. Jinglin Xia
Liver Cancer Institute, Zhongshan Hospital, Fudan University; Key Laboratory of Carcinogenesis and Cancer Invasion, Ministry of Education, 180 Fenglin Road, Xuhui District, Shanghai 200032 (China) and Minhang District Central Hospital, 170 Xinsong Road, Minhang District, Shanghai 201199 (China)

Tel. +86-021-54237681, Fax +86-021-64037318, E-Mail xiajinglin@fudan.edu.cn 


\section{Cellular Physiology and Biochemistry}

Cell Physiol Biochem 2014;34:1536-1546

DOI: $10.1159 / 000366357$

(C) 2014 S. Karger AG, Basel

www.karger.com/cpb

Tian et al.: Hypoxia Promotes Hepatocarcinoma Progression and Metastasis

\section{Introduction}

Hepatocellular carcinoma (HCC) is one of the most common cancers and the third leading cause of cancer related death worldwide [1]. Despite advances in the early detection of HCC and the development of various combination treatments including surgery, radiotherapy and chemotherapy, the prognosis of patients with HCC remains poor. Most patients are in an advanced stage of disease at the time of diagnosis and only approximately $30-40 \%$ of patients show a positive response to therapy [2]. The overall 5-year survival rate is low because of the high incidence of recurrence and metastasis after hepatic resection [3], underscoring the importance of the identification of novel therapeutic targets and effective treatments. Recent studies showed that hypoxia promotes HCC invasion and progression in association with the overexpression or stabilization of hypoxia-inducible factor-1 (HIF-1) [4, 5].

Hypoxia plays a critical role in cancer and hypoxia inducible factors are important mediators of the hypoxic response [6]. The HIF-1 heterodimer complex, which contains two basic helix-loop-helix transcription factors, HIF-1 $\alpha$ and HIF-1 [7], activates the transcription of target genes under conditions of hypoxia [8]. In cancer, intratumoral hypoxia associated with the activation of HIF- $1 \alpha$ is an important mechanism that promotes tumor aggressiveness, metastasis and patient mortality [9]. HIF-1 $\alpha$ regulates the expression of various chemokines $[10,11]$, and chemokines and their receptors facilitate tumor dissemination by promoting proliferation, angiogenesis, and by activating survival pathways [12].

CXCL6 [granulocyte chemotactic protein-2 (GCP2)] is a member of the CXC chemokine family, which is characterized by the presence of four conserved cysteine residues near the amino terminus forming the Cys-X-Cys or "CXC" motif [13]. The CXC chemokine family is divided into ELR+ and ELR- chemokines based on the presence or absence of the amino acid sequence Glu-Leu-Arg (ELR) [14]. CXCL6 is an ELR+ chemokine with neutrophil chemotactic and angiogenic properties similar to those of interleukin-8 (IL-8), with which it shares $31 \%$ amino acid sequence homology and the ability to attract granulocytes and stimulate the secretion of proteases such as matrix-metalloproteinase-9 (MMP-9) from its granules [15-17] . CXCL6 and IL-8 bind to the G-protein coupled receptors CXCR1 and CXCR2, which mediate their chemotactic and angiogenic activities [18]. In the present study, we show that HIF- $1 \alpha$ is upregulated in HCC cell lines and tissues and its effect on promoting invasion and metastasis is mediated by its direct interaction with the pro-angiogenic chemokine CXCL6. Our results shed light on the role of hypoxia in the pathogenesis and progression of HCC and suggest a potential new target for the treatment of patients with HCC.

\section{Materials and Methods}

\section{Ethics statement}

Ethical approval was obtained from Zhongshan Hospital research ethics committee.

Written informed consent from the donor or the next of kin was obtained for use of primary HCC samples in this research.

\section{Patients and tissue specimens}

Primary HCC samples ( $n=129)$ were obtained between June 2005 and December 2009 from patients who had undergone curative hepatectomy and were diagnosed with abdominal lymph node metastases (LNMs) during follow-up care at Zhongshan Hospital. Patients were followed-up for 84 months.

\section{Cell culture}

The human HCC cell lines Huh7, HepG2, and the control liver cell line Chang Liver were purchased from Shanghai Institute of Biological Sciences, Chinese Academy of Sciences. The HCC cell lines MHCC97L and MHCC97H were established at the Liver Cancer Institute of Fudan University, Shanghai The human embryonic kidney cell line HEK293 was purchased from Microbix Biosystems (Toronto, ON, Canada). The cells were cultured in Dulbecco's modified Eagle's medium supplemented with 10\% FBS (GIBCO-BRL) in 


\section{Cellular Physiology and Biochemistry}

Cell Physiol Biochem 2014;34:1536-1546

\begin{tabular}{l|l}
\hline DOI: $10.1159 / 000366357$ & (C) 2014 S. Karger AG, Basel
\end{tabular}

Tian et al.: Hypoxia Promotes Hepatocarcinoma Progression and Metastasis

humidified 5\% CO2, 95\% air at 37oC. For hypoxic experiments, the cells were incubated in a humidified Heto multigas incubator in $0.5 \% 02,5 \% \mathrm{CO} 2$ and $95 \% \mathrm{~N} 2$.

\section{Immunohistochemistry}

Immunohistochemical staining was performed using the avidin-biotin peroxidase complex method as described previously. Briefly, after rehydration and microwave antigen retrieval, slides were incubated in monoclonal antibodies against HIF- $1 \alpha$ (BD Clontech, USA) and CXCL6 at $4^{\circ} \mathrm{C}$ overnight followed by incubation in the corresponding secondary antibodies at $37^{\circ} \mathrm{C}$ for $30 \mathrm{~min}$. Staining was performed with DAB and counter-staining with Mayer's hematoxylin. Negative controls were performed by omitting the primary antibodies.

\section{RNA isolation and $q R T-P C R$}

Total RNA was extracted from cell lines and frozen tissue specimens using the Trizol reagent (Invitrogen, Carlsbad, CA) according to the manufacturer's protocol. Reverse transcription was performed using the PrimeScript RT reagent kit (TaKaRa, Dalian China) according to the manufacturer's instructions. For qRT-PCR, cDNA aliquots were amplified using SYBR Premix Ex Taq (TaKaRa). PCR reactions were performed in triplicate under the following conditions: $95^{\circ} \mathrm{C} / 30 \mathrm{~s}, 40$ cycles of $95^{\circ} \mathrm{C} / 5 \mathrm{~s}, 60^{\circ} \mathrm{C} / 15 \mathrm{~s}$ and $72^{\circ} \mathrm{C} / 10 \mathrm{~s}$ on an MXP3000 cycler (Stratagene, Santa Clara, CA). Relative mRNA levels were calculated using the ${ }^{-\Delta \Delta} \mathrm{Ct}$ method using $\beta$-actin as the control and expressed as $2^{\wedge}\left({ }^{-\Delta \Delta} \mathrm{Ct}\right)$. The sequences of the primers used to amplify specific gene products were as follows: HIF-1 $\alpha$ sense, $5^{\prime}$ - GAACGTCGAAAAGAAAAGTCTC-3'; HIF$1 \alpha$ antisense, 5'-CCTTATCAAGATGCGAACTCACA-3'; CXCL6 sense, 5'-AGAGCTGCGTTGCACTTGTT-3'; CXCL6 antisense, 5'-GCAGTTTACCAAT CGTTTTGGGG-3:

\section{Western Blot Analysis}

Western blotting was performed using routine protocols. Briefly, total cell lysates were separated on a 16.5\% Tris-Tricine gelfor CXCL6 or 10\% SDS-PAGE for other proteins and proteins were transferred to polyvinylidene difluoride membranes. After washing and blocking in phosphate buffered saline containing $5 \%$ nonfat dry milk, membranes were incubated in the indicated primary antibodies followed by incubation in horseradish-peroxidase conjugated secondary antibodies. $\beta$-actin was used as the loading control. Bands were detected using enhanced chemiluminescence.

\section{Cell migration and invasiveness assays}

For wound healing migration assays, cells were grown in a monolayer to approximately $60 \%$ confluency. A cell-less strip was generated by scraping the cells off the middle of the monolayer with a 200$\mu$ pipette tip. Wound closure was monitored at the time of wounding ( 0 hour) and at $24 \mathrm{~h}$ after wounding using microphotography $(\times 10$ magnification) under a Leica DM IRE2 microscope (Leica Microsystems Imaging Solutions Ltd, Cambridge, UK). The assay was repeated three times. For Transwell invasion assays, Matrigel (BD Biosciences, Franklin Lakes, NJ) was allowed to polymerize at the base of the top chamber of a 24 well Transwell plate ( $8 \mu \mathrm{m}$, Corning Costar Corp, Corning, NY) for $45 \mathrm{~min}$ at $37^{\circ} \mathrm{C}$. Cells $\left(1 \times 10^{5}\right.$ cells $/$ well) were serum and growth factor starved for $24 \mathrm{~h}$ and added to the top chambers. The bottom chambers were filled with serum-containing medium. Cultures were maintained for $48 \mathrm{~h}$ and then non-invading cells were removed from the upper surface of the membrane with cotton swabs. Invading cells were fixed in $4 \%$ paraformaldehyde, stained with $0.1 \%$ crystal violet for $15 \mathrm{~min}$ at room temperature and counted in 10 fields under a $\times 100$ objective and the mean \pm SD was calculated. Assays were performed in triplicate wells and repeated twice.

\section{Adenoviral vector-mediated HIF-1 $\alpha$ silencing}

RNA interference mediated HIF-1 $\alpha$ silencing was performed as described previously [4]. Briefly, shRNA targeting HIF-1 $\alpha$ was generated with the primers 5'-aGTCGGACAGCCTCACCAAAtttt-3' (forward) and 5'-aTTTGGTGAGGCTGT CCGACtttt-3‘ (reverse), which were used to generate HIF-1 $\alpha$ siRNA pSES-HUS. The construct was used to generate the recombination plasmid pAdeasy-HIF-1 $\alpha$ siRNA, which was transfected into HEK293 cells to produce recombinant adenovirus Ad-HIF- $1 \alpha$ siRNA. A control adenovirus containing a non-functional shRNA (Ad-scramble) was also produced. The adenoviruses were harvested and purified using $\mathrm{CsCl}$ gradient centrifugation. 


\section{Cellular Physiology and Biochemistry}

Cell Physiol Biochem 2014;34:1536-1546

\begin{tabular}{l|l}
\hline DOI: $10.1159 / 000366357$ & (C) 2014 S. Karger AG, Basel
\end{tabular}

www.karger.com/cpb

Tian et al.: Hypoxia Promotes Hepatocarcinoma Progression and Metastasis

\section{Luciferase reporter vector construction}

Genomic DNA from normal human livers was used as a template to amplify the promoter of the CXCL6 gene (PCR primers, sense: 5'- GCC GCT CGG CTC TTC ACT CC -3' and antisense: 5'- CCA CAA GCT GTC CAC TGA TGC CG - $3^{\prime}$ ). The PCR products were digested by KpnI and HindIII, and cloned downstream of the luciferase reporter gene of a pGL3 basic vector (Promega, Madison, WI). To generate the pGL3-CXCL6-Mut construct, the HIF-1 $\alpha$ binding site on the CXCL6 promoter was eliminated by mutating five bases in the putative hypoxia response element (HRE) (CAGGTACTGTCC $\rightarrow$ TAGGACCTATGC). This was achieved by primer-driven site-directed mutagenesis using a CXCL6 promoter (-803) luciferase reporter as the template.The resulting plasmids harboring various lengths of the CXCL6 promoter or a mutant promoter were transfected into Huh-7, HepG2, MHCC97L and MHCC97H cells. Luciferase activity was determined and compared to that of vector transfected cells.

\section{Chromatin immunoprecipitation (ChIP)}

An anti-HIF-1 $\alpha$ monoclonal antibody (R\&D system, Minneapolis, USA) was used to immunoprecipitate sonicated chromatins prepared from HCC cell lines. Pre-immune IgG was used as a control. Immunoprecipitated DNA was quantified for the CXCL6 promoter segments using qRT-PCR. The sequences of the primers were as follows: forward primer, 5'- ACGAATGGTTCAACTTCCAGTG-3'; reverse primer, 5'-TCCTCСAACTTCTA ACCACCAC-3'

\section{Statistical analysis}

Statistical analyses were performed using SPSS 13.0. Kaplan-Meier analysis was used to determine survival and the two-sided log-rank test was used to compare differences. The Pearson $\chi 2$ test or Fisher's exact test was used to compare qualitative variables and the Student's $t$ test was used for quantitative variables. A P value $<0.05$ was considered statistically significant.

\section{Results}

\section{HIF-1 $\alpha$ expression is upregulated in human hepatocarcinoma}

The levels of expression of HIF-1 $\alpha$ were assessed in primary HCC samples from 129 patients who had undergone curative hepatectomy. No significant correlation between CXCL6 expression and the clinicopathological features of HCC patients was observed except for TNM stage and microvascular invasion, which were positively correlated with CXCL6 expression levels. Figure 1 shows representative IHC images of paraffin-embedded sections showing increased HIF-1 $\alpha$ expression in HCC compared to peritumoral liver tissue sections (Fig. 1A). HIF-1 $\alpha$ mRNA levels were assessed by qRT-PCR in human HCC cell lines with the same genetic background but high and low metastatic potential (MHCC97H and MHCC97L, respectively) and in the low metastatic potential cell lines HepG2 and Huh7 in comparison to the control liver cell line Chang Liver. For hypoxic culture conditions, the cells were incubated in a humidified Heto multigas incubator in $0.5 \% \mathrm{O}_{2}, 5 \% \mathrm{CO}_{2}$ and $95 \% \mathrm{~N}_{2}$. HIF- $1 \alpha$ expression was significantly increased in all HCC lines, with MHCC97H cells showing the highest HIF-1 $\alpha$ mRNA levels (Fig. 1B). These results were confirmed by western blot analysis, which showed significantly higher HIF-1 $\alpha$ protein expression in HCC cells than in the Chang Liver cell line (Fig. 1C).

\section{HIF-1 $\alpha$ modulates CXCL6 expression in hepatocarcinoma cell lines}

Because HIF- $1 \alpha$ is a known regulator of the transcription of genes associated with angiogenesis in solid tumors, we examined the effect of HIF-1 $\alpha$ silencing on the expression of CXCL6 in four HCC cell lines (Huh7, HepG2, MHCC97L and MHCC97H). Small hairpin RNA (shRNA) mediated silencing of HIF-1 $\alpha$ significantly decreased the levels of HIF-1 $\alpha$ mRNA compared to untreated controls or scramble RNA transfected cells (Fig. 2A) and resulted in a significant downregulation of CXCL6 mRNA expression in all cell lines (Fig. 2B). Western blot analysis of the expression of the HIF- $1 \alpha$ and CXCL6 proteins in response to HIF- $1 \alpha$ silencing showed that the decrease of HIF- $1 \alpha$ protein level was correlated with a significant downregulation of CXCL6 expression in all cell lines (Fig. 2C). 


\section{Cellular Physiology and Biochemistry}

Cell Physiol Biochem 2014;34:1536-1546

\begin{tabular}{|l|l|}
\hline DOI: $10.1159 / 000366357$ & C 2014 S. Karger AG, Basel
\end{tabular}

www.karger.com/cpb

Tian et al.: Hypoxia Promotes Hepatocarcinoma Progression and Metastasis

Fig 1. HIF-1 $\alpha$ expression is upregulated in human hepatocarcinoma (HCC) (A) Representative immunohistochemistry images of human HCC sections stained for HIF-1 $\alpha$ (magnification, $\times 100$ ). (B) HIF- $1 \alpha$ mRNA expression in hepatocarcinoma cell lines and the Chang Liver cell line. RNA levels were normalized to $18 \mathrm{~S}$ rRNA. Results are expressed as mean \pm SEM $(\mathrm{n}=3) * \mathrm{P}<0.05$. (C) HIF-1 $\alpha$ protein expression in HCC cell lines and the Chang Liver cell line. $\beta$-actin was used as the loading control.
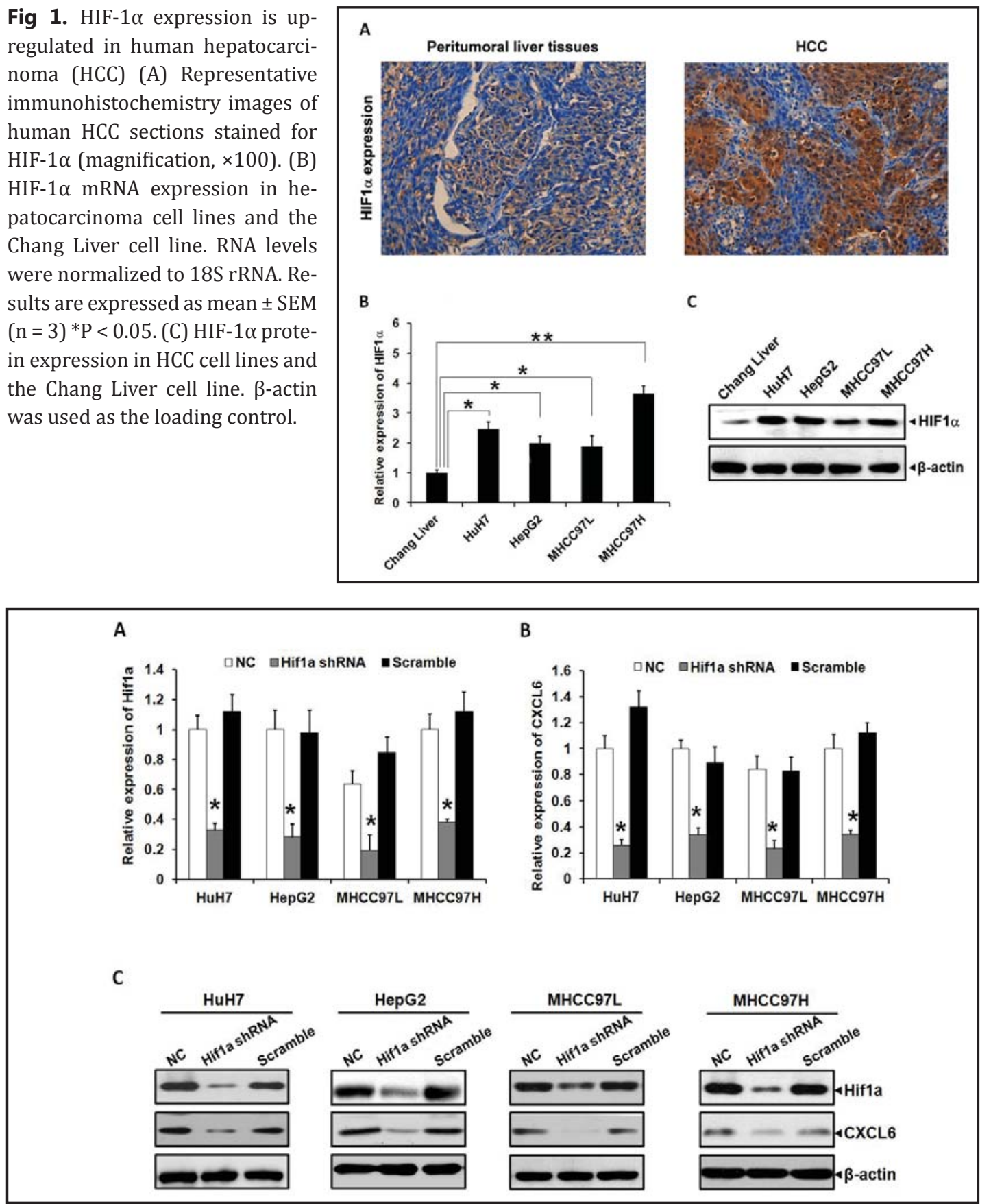

Fig. 2. HIF-1 $\alpha$ regulates CXCL6 expression in hepatocarcinoma cell lines (A) Efficiency of HIF-1 $\alpha$ knockdown in HCC cell lines (HuH7, HepG2, MHCC97L, MHCC97H) was evaluated by qRT-PCR. (B) qRT-PCR analysis of CXCL6 expression in response to HIF- $1 \alpha$ knock-down in HCC cells. (C) Western blot detection of HIF-1 $\alpha$ and CXCL6 protein expression in HCC cell lines treated with shRNA against HIF-1 $\alpha$.

\section{HIF-1 $\alpha$ promotes CXCL6 transcriptional activation}

To further examine the regulation of CXCL6 expression by HIF- $1 \alpha$, the sequence of the CXCLC6 promoter was screened and promoter-luciferase constructs were generated based on the location of the putative hypoxia response element (HRE) (Fig. 3A). Luciferase activity was quantified after transfection of truncated (P1-P3) or mutant (M) CXCL6 promoterdriven vectors into HCC cells Results were expressed relative to the luciferase activity of vector control transfected cells (Fig. 3B). The results showed luciferase activity in the 


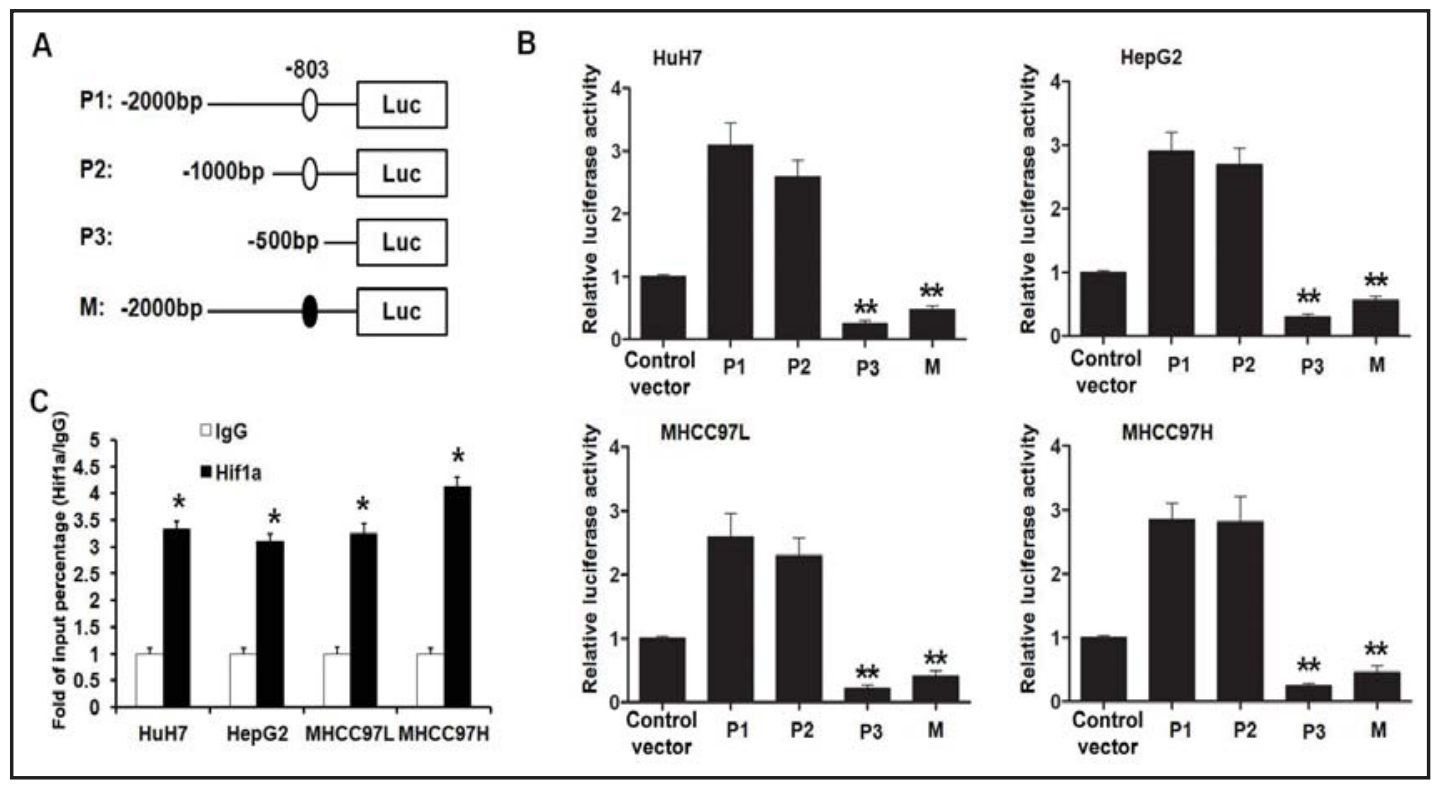

Fig. 3. HIF-1 $\alpha$ promotes CXCL6 transcriptional activation. (A) Schematic illustration of CXCL6 promoterluciferase constructs showing the location of the hypoxia response element (HRE). (B) The HCC cell lines HuH7, HepG2, MHCC97L, and MHCC97 were transfected with pGL3-basic vector or a series of pGL3 vectors containing truncated CXCL6 promoters (P1, P2, P3) or promoters with mutated HRE(M), along with the Renilla luciferase expression vector. Firefly luciferase activity was measured after $48 \mathrm{~h}$ and normalized to that of Renilla luciferase. Data are expressed as mean \pm SD of three independent experiments. Data are expressed relative to the luciferase activity of vector control transfected cells. (C) Results of ChIP-qRT-PCR with sonicated chromatins immunoprecipitated from HCC cell lines using an anti-HIF-1 $\alpha$ monoclonal antibody or pre-immune IgG (control) showing the association of HIF-1 $\alpha$ with the CXCL6 promoter. CXCL6 promoter segments were quantified using qRT-PCR.Data are expressed as the mean \pm SD from three independent experiments.

promoters containing the putative HRE (P1 and P2), whereas those without the HRE (P3) or with a mutant HRE site (M) lost transcriptional activity in all HCC cell lines. To confirm the binding of HIF- $1 \alpha$ to the promoter of CXCL6, ChIP-qRT-PCR was performed using sonicated chromatins immunoprecipitated from HCC cell lines using an anti- HIF-1 $\alpha$ antibody or an IgG control, which showed that HIF-1 $\alpha$ directly associated with the CXCL6 promoter region in the four HCC lines tested (Fig. 3C). Taken together, these results indicated that HIF-1 $\alpha$ binds to the promoter of CXCL6 and activates its transcription.

\section{HIF-1 $\alpha$ induced migration and invasion of HCC cells is dependent on CXCL6 expression}

To examine the effects of HIF- $1 \alpha$ on the biological behavior of HCC cells, wound healing assays were performed after hypoxia induction in the low and high metastatic potential cell lines Huh7 and MHCC97H. The results showed that HIF-1 $\alpha$ significantly promoted the migration of HCC cells, whereas treatment with an anti-CXCL6 antibody reversed this effect (Fig. 4A). A Transwell assay was used to examine the effect of CXCL6 on invasion in the highly metastatic cell line MHCC $97 \mathrm{H}$, which showed that HIF-1 $\alpha$ significantly increased the number of cells invading into the lower surface of the Transwell membrane, and treatment with an anti-CXCL6 antibody significantly inhibited this effect (Fig. 4B). Taken together, these results indicate that the HIF-1 $\alpha$ induced invasion and migration of HCC cells is dependent on CXCL6 expression.

CXCL6 upregulation in HCC is correlated with poor prognosis

The biological significance of CXCL6 was further examined in primary HCC samples obtained from patients who had undergone curative hepatectomy and were diagnosed with 


\section{Cellular Physiology and Biochemistry}

Cell Physiol Biochem 2014;34:1536-1546

Tian et al.: Hypoxia Promotes Hepatocarcinoma Progression and Metastasis

Fig. 4. HIF- $1 \alpha$ promotes migration and invasion of HCC cells in vitro in a CXCL6 dependent manner. (A) Wound healing assays showing the effects of HIF- $1 \alpha$ stabilization on the migration of $\mathrm{HuH7}$ and MHCC-97H cells in the presence or absence of an anti-CXCL6 antibody. (B) Transwell assays showing the effects of HIF- $1 \alpha$ stabilization on the invasiveness of MHCC-97H cells in the presence or absence of an anti-CXCL6 antibody. The numbers of invasive MHCC97H cells in normoxia or hypoxia and antiCXCL6 antibody were calculated using crystal violet staining. The average of six random microscopic fields $(\times 400)$ was recorded. Data are expressed as the mean \pm SD of three independent experiments. Representative images are shown.

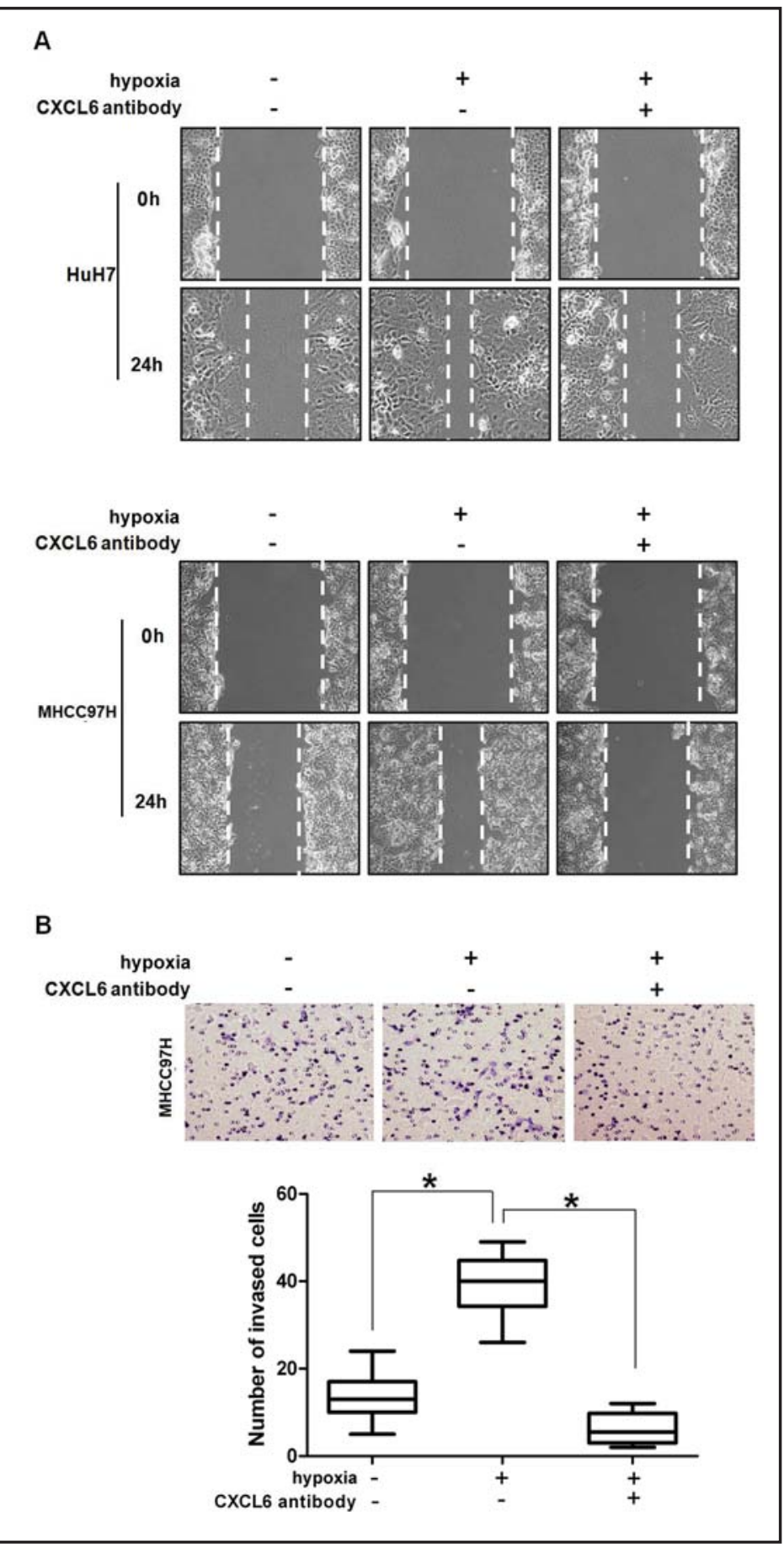

abdominal LNMs. The clinicopathological characteristics of the 129 patients are included in the analysis (112 men and 17 women with a mean age of 56.2). Patients were divided into two groups according to the level of expression of CXCL6, namely low ( $\mathrm{n}=67)$ and high $(n=62)$ expressing groups. Patients with high CXCL6 expression showed a greater number of tumors, more frequent microvascular invasion and higher tumor grade $(P<0.01)$.

Disease free survival and recurrence probability were compared in these groups during the 84 month follow-up period. Kaplan-Meier survival analysis curves showed that high CXCL6 levels were associated with decreased overall survival and an increased probability 


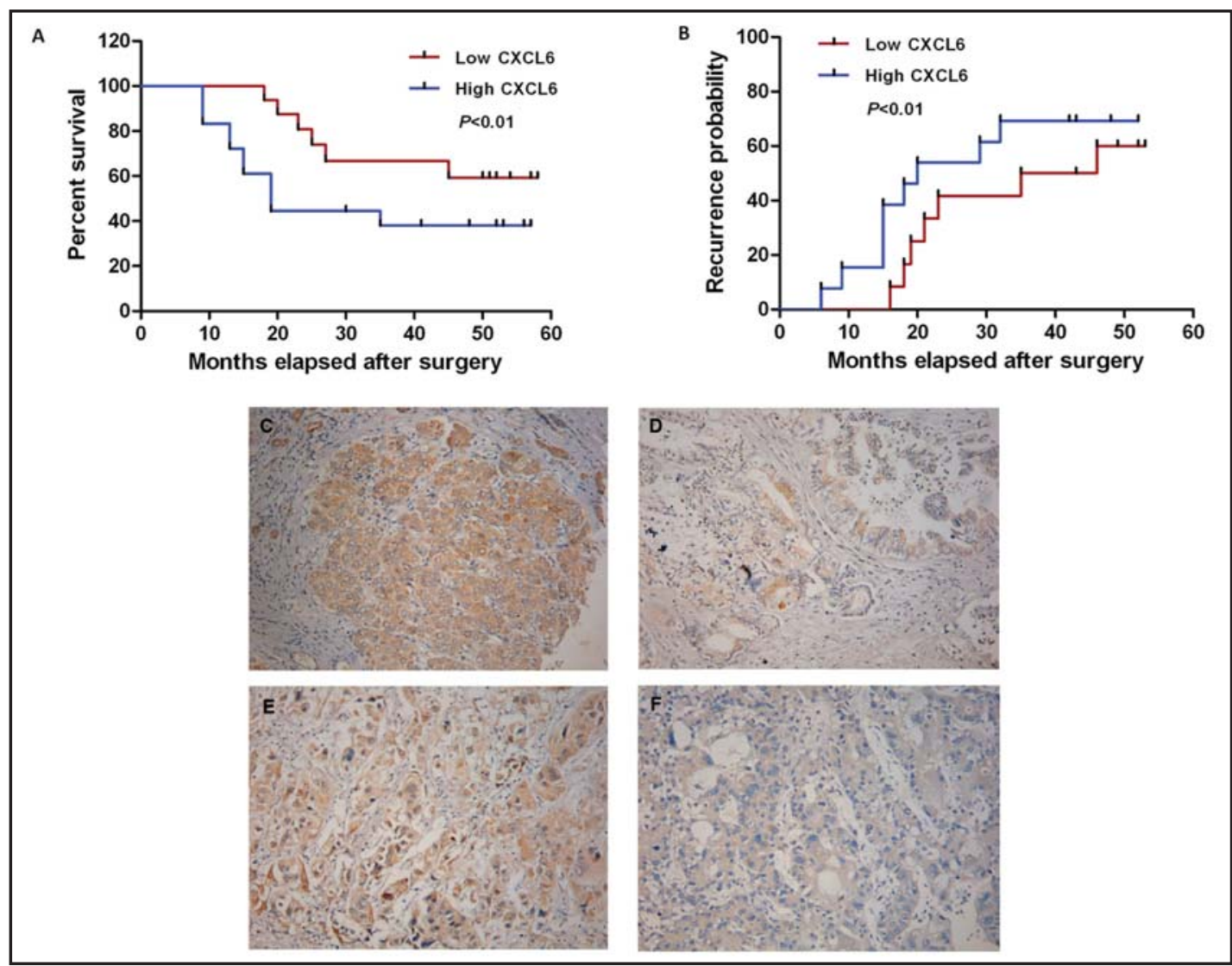

Fig. 5. CXCL6 upregulation in HCC is correlated with poor prognosis. Disease-free survival (A) and recurrence probability (B) after surgery were compared between HCC patients with high CXCL6 expression $(n=67)$ and low CXCL6 expression $(n=62)$. $(C-F)$ Representative immunohistochemistry images showing the levels of CXCL6 in the high CXCL6 expressing (C, E) and low CXCL6 expressing (D, F) groups (C, D: $\times 200$; E, F: $\times 400)$.

of recurrence (Fig. $5 \mathrm{~A}$ and $\mathrm{B})(P<0.01)$. Figure $5 \mathrm{C}-\mathrm{F}$ shows representative images showing the expression levels of CXCL6 at different magnifications in high ( $\mathrm{C}$ and $\mathrm{E}$ ) and low (D and F) CXCL6 expressing tissue samples.

\section{Discussion}

The chemoattraction theory proposes that organ-specific attractant molecules stimulate the migration of tumor cells to invade the walls of blood vessels and enter organs [19]. Among these chemoattractants, chemokines and their receptors have been implicated in several aspects of tumor biology including migration/invasion and angiogenesis. Furthermore, chemotaxis is affected by oxygen availability and the effect of hypoxia and hypoxia inducible factors in the regulation of metastasis has been investigated extensively. In the present study, we examined the role of HIF- $1 \alpha$ in HCC and showed that the effect of hypoxia on the progression and metastasis of HCC is at least partly mediated by the regulation of CXCL6 expression by HIF- $1 \alpha$.

HIF- $1 \alpha$ was upregulated in HCC cell lines and its expression was correlated with the levels of CXCL6, as shown by the downregulation of CXCL6 in response to HIF-1 $\alpha$ silencing. HIF-1 $\alpha$ was previously shown to be overexpressed in HCC [20] and its involvement in the malignant transformation of hepatocytes suggests that it plays a role in hepatocarcinogenesis [21]. However, several molecules mediate the effect of HIF-1 $\alpha$ in different cancers and its 


\section{Cellular Physiology and Biochemistry}

Cell Physiol Biochem 2014;34:1536-1546

\begin{tabular}{l|l}
\hline DOI: $10.1159 / 000366357$ & (c) 2014 S. Karger AG, Basel
\end{tabular}

www.karger.com/cpb

1544

Tian et al.: Hypoxia Promotes Hepatocarcinoma Progression and Metastasis

specific tumor-promoting mechanisms in HCC remain unclear. Murata et al. showed that HIF- $1 \alpha$ overexpression is associated with the production of an abnormal prothrombin, des$\gamma$-carboxyl prothrombin or DCP, a known tumor marker in HCC [22], and HIF-1 $\alpha$ promotes angiogenesis and metastasis via the upregulation of vascular endothelial growth factor (VEGF) and matrix metalloproteinases [23, 24]. The effect of hypoxia on chemokines and their ligands was examined by Muller et al., who showed that the role of hypoxia in metastasis is mediated by its effect on the chemokine receptor CXCR4, which controls the metastatic homing of tumor cells to organs expressing high levels of its ligand SDF1 [25]. CXCR4 is upregulated by hypoxia in different types of cells and tumors via HIF-1 $\alpha[26,27]$ and the involvement of the CXCL12/CXCR4 axis in metastasis has been shown in breast cancer, non-small cell lung cancer and prostate cancer $[25,28,29]$. In small cell lung cancer, the expression of CXCL6 is upregulated by IL-1 $\beta$ and hypoxia [30]. In acute myeloid leukemia (AML), hypoxic conditions alter the cytokine expression profile of AML cells, which release increased levels of various cytokines including CXCL1, CXCL8, CCL34, CCL7 as well as VEGF and osteopontin [31]. Furthermore, hypoxia upregulates HIF-1 $\alpha$ in correlation with increased VEGF release and the upregulation of CCL and CXC chemokines. These studies showing the hypoxia-related involvement of chemokines and their receptors in cancer cell proliferation and migration support the present findings and warrant further investigation to determine whether HIF- $1 \alpha$ could trigger a broad chemokine response associated with the aggressiveness and prognosis of different cancers.

CXCL6 was first identified in a human osteosarcoma cell line [17] and has been implicated in the pathogenesis and progression of several malignancies including breast cancer, gastrointestinal tumors and prostate cancer $[19,32,33]$. CXCL6 inhibition suppressed tumor growth and metastasis in a murine model of melanoma, confirming the role of the chemokine in the promotion of tumor cell survival, proliferation and invasion [34]. Furthermore, the angiogenic effect of CXCL6 is correlated with the intratumoral expression of MMP-9, and the release of MMP-9 as a result of neutrophil degradation promotes tumor invasion through the degradation of the extracellular matrix [35]. Similar results were reported for other chemokines such as CXCL8 and CXCL12, which exert their pro-angiogenic and metastatic effects through the upregulation of MMP-9 [36], providing a possible mechanism mediating the effect of CXCL6 on metastasis.

In the present study, we showed that the effect of HIF-1 $\alpha$ on the promotion of cell migration and invasion was dependent on CXCL6, and overexpression of CXCL6 in HCC tissues was correlated with poor prognosis. Similar results were reported in a study examining the role of CXCL5 in HCC, which showed a strong correlation between the expression of the chemokine and the prognosis of HCC patients [37]. However, the exact involvement of CXC chemokines including CXCL6 in cancer progression remains unclear, and the overexpression of CXCL6 in HCC is not fully understood.

In conclusion, we showed that HIF- $1 \alpha$ is upregulated in HCC and modulates the expression of the pro-angiogenic chemokine CXCL6 via direct interaction with an HRE in its promoter. Furthermore, induction of HIF- $1 \alpha$ by hypoxia promoted HCC migration and invasion in vitro in a CXCL6 dependent manner, and CXCL6 expression was correlated with poor prognosis, suggesting that it could serve as a potential therapeutic target for the treatment of HCC.

\section{Acknowledgments}

The work was supported by Shanghai Leading Academic Discipline Project (14XD1401100), The National Nature Science Foundation of China (81272732, 81101804), The Shanghai Committee of Science and Technology (A241014003) and Shanghai Health Bureau Research Fund (No.2010/50, XBR2011002). 


\section{Cellular Physiology and Biochemistry}

Cell Physiol Biochem 2014;34:1536-1546

\begin{tabular}{l|l}
\hline DOI: $10.1159 / 000366357$ & (C) 2014 S. Karger AG, Basel
\end{tabular}

www.karger.com/cpb

Tian et al.: Hypoxia Promotes Hepatocarcinoma Progression and Metastasis

\section{References}

1 El-Serag HB, Rudolph KL: Hepatocellular carcinoma: Epidemiology and molecular carcinogenesis. Gastroenterology 2007;132:2557-2576.

2 Llovet JM, Burroughs A, Bruix J: Hepatocellular carcinoma. Lancet 2003;362:1907-1917.

-3 Poon RT, Fan ST, Lo CM, Liu CL, Wong J: Long-term survival and pattern of recurrence after resection of small hepatocellular carcinoma in patients with preserved liver function: Implications for a strategy of salvage transplantation. Ann Surg 2002;235:373-382.

-4 Zhang L, Huang G, Li X, Zhang Y, Jiang Y, Shen J, Liu J, Wang Q, Zhu J, Feng X, Dong J, Qian C: Hypoxia induces epithelial-mesenchymal transition via activation of snai1 by hypoxia-inducible factor -1alpha in hepatocellular carcinoma. BMC Cancer 2013;13:108.

-5 Liu Y, Zhang JB, Qin Y, Wang W, Wei L, Teng Y, Guo L, Zhang B, Lin Z, Liu J, Ren ZG, Ye QH, Xie Y: Prox1 promotes hepatocellular carcinoma metastasis by way of up-regulating hypoxia-inducible factor 1alpha expression and protein stability. Hepatology 2013;58:692-705.

6 Yang MH, Wu KJ: Twist activation by hypoxia inducible factor-1 (hif-1): Implications in metastasis and development. Cell Cycle 2008;7:2090-2096.

7 Wang GL, Jiang BH, Rue EA, Semenza GL: Hypoxia-inducible factor 1 is a basic-helix-loop-helix-pas heterodimer regulated by cellular o2 tension. Proc Nat Acad Sci USA 1995;92:5510-5514.

8 Semenza GL, Jiang BH, Leung SW, Passantino R, Concordet JP, Maire P, Giallongo A: Hypoxia response elements in the aldolase a, enolase 1 , and lactate dehydrogenase a gene promoters contain essential binding sites for hypoxia-inducible factor 1. J Biol Chem 1996;271:32529-32537.

-9 Maxwell PH: The hif pathway in cancer. Semin Cell Dev Biol 2005;16:523-530.

10 Mojsilovic-Petrovic J, Callaghan D, Cui H, Dean C, Stanimirovic DB, Zhang W: Hypoxia-inducible factor-1 (hif-1) is involved in the regulation of hypoxia-stimulated expression of monocyte chemoattractant protein-1 (mcp-1/ccl2) and mcp-5 (ccl12) in astrocytes. J Neuroinflammation 2007;4:12.

-11 Baay-Guzman GJ, Bebenek IG, Zeidler M, Hernandez-Pando R, Vega MI, Garcia-Zepeda EA, AntonioAndres G, Bonavida B, Riedl M, Kleerup E, Tashkin DP, Hankinson O, Huerta-Yepez S: Hif-1 expression is associated with ccl2 chemokine expression in airway inflammatory cells: Implications in allergic airway inflammation. Respir Res 2012;13:60.

12 Koizumi K, Hojo S, Akashi T, Yasumoto K, Saiki I: Chemokine receptors in cancer metastasis and cancer cell-derived chemokines in host immune response. Cancer Sci 2007;98:1652-1658.

13 Mehrad B, Keane MP, Strieter RM: Chemokines as mediators of angiogenesis. Thromb Haemost 2007;97:755-762.

14 Popivanova BK, Koike K, Tonchev AB, Ishida Y, Kondo T, Ogawa S, Mukaida N, Inoue M, Yamashima T: Accumulation of microglial cells expressing elr motif-positive cxc chemokines and their receptor cxcr2 in monkey hippocampus after ischemia-reperfusion. Brain Res 2003;970:195-204.

-15 Strieter RM, Polverini PJ, Kunkel SL, Arenberg DA, Burdick MD, Kasper J, Dzuiba J, Van Damme J, Walz A, Marriott D, et al.: The functional role of the elr motif in cxc chemokine-mediated angiogenesis. J Biol Chem 1995;270:27348-27357.

16 Strieter RM, Burdick MD, Mestas J, Gomperts B, Keane MP, Belperio JA: Cancer cxc chemokine networks and tumour angiogenesis. Eur J Cancer (Oxford, England : 1990) 2006;42:768-778.

17 Proost P, De Wolf-Peeters C, Conings R, Opdenakker G, Billiau A, Van Damme J: Identification of a novel granulocyte chemotactic protein (gcp-2) from human tumor cells. In vitro and in vivo comparison with natural forms of gro, ip-10, and il-8. J Immunology (Baltimore, Md : 1950) 1993;150:1000-1010.

-18 Keane MP, Burdick MD, Xue YY, Lutz M, Belperio JA, Strieter RM: The chemokine receptor, cxcr2, mediates the tumorigenic effects of elr+ cxc chemokines. Chest 2004;125:133S.

-19 Cronin PA, Wang JH, Redmond HP: Hypoxia increases the metastatic ability of breast cancer cells via upregulation of cxcr4. BMC Cancer 2010;10:225.

20 Tanaka H, Yamamoto M, Hashimoto N, Miyakoshi M, Tamakawa S, Yoshie M, Tokusashi Y, Yokoyama K, Yaginuma Y, Ogawa K: Hypoxia-independent overexpression of hypoxia-inducible factor 1alpha as an early change in mouse hepatocarcinogenesis. Cancer Res 2006;66:11263-11270.

-21 Yao DF, Jiang H, Yao M, Li YM, Gu WJ, Shen YC, Qiu LW, Wu W, Wu XH, Sai WL: Quantitative analysis of hepatic hypoxia-inducible factor-1alpha and its abnormal gene expression during the formation of hepatocellular carcinoma. Hepatobiliary Pancreat Dis Int 2009;8:407-413. 


\section{Cellular Physiology and Biochemistry}

Cell Physiol Biochem 2014;34:1536-1546

\begin{tabular}{l|l}
\hline DOI: $10.1159 / 000366357$ & (C) 2014 S. Karger AG, Basel
\end{tabular}

Tian et al.: Hypoxia Promotes Hepatocarcinoma Progression and Metastasis

-22 Murata K, Suzuki H, Okano H, Oyamada T, Yasuda Y, Sakamoto A: Hypoxia-induced des-gamma-carboxy prothrombin production in hepatocellular carcinoma. Int J Oncol 2010;36:161-170.

-23 Sullivan R, Graham CH: Hypoxia-driven selection of the metastatic phenotype. Cancer Metastasis Rev 2007;26:319-331.

-24 Shyu KG, Hsu FL, Wang MJ, Wang BW, Lin S: Hypoxia-inducible factor 1alpha regulates lung adenocarcinoma cell invasion. Exp Cell Res 2007;313:1181-1191.

25 Muller A, Homey B, Soto H, Ge N, Catron D, Buchanan ME, McClanahan T, Murphy E, Yuan W, Wagner SN, Barrera JL, Mohar A, Verastegui E, Zlotnik A: Involvement of chemokine receptors in breast cancer metastasis. Nature 2001;410:50-56.

26 Schioppa T, Uranchimeg B, Saccani A, Biswas SK, Doni A, Rapisarda A, Bernasconi S, Saccani S, Nebuloni M, Vago L, Mantovani A, Melillo G, Sica A: Regulation of the chemokine receptor cxcr4 by hypoxia. J Exper Med 2003;198:1391-1402.

-27 Schutyser E, Su Y, Yu Y, Gouwy M, Zaja-Milatovic S, Van Damme J, Richmond A: Hypoxia enhances cxcr4 expression in human microvascular endothelial cells and human melanoma cells. Eur Cytokine Netw 2007;18:59-70.

28 Phillips RJ, Burdick MD, Lutz M, Belperio JA, Keane MP, Strieter RM: The stromal derived factor-1/cxcl12cxc chemokine receptor 4 biological axis in non-small cell lung cancer metastases. Am J Respir Crit Care Med 2003;167:1676-1686.

29 Taichman RS, Cooper C, Keller ET, Pienta KJ, Taichman NS, McCauley LK: Use of the stromal cell-derived factor-1/cxcr4 pathway in prostate cancer metastasis to bone. Cancer Res 2002;62:1832-1837.

30 Zhu YM, Bagstaff SM, Woll PJ: Production and upregulation of granulocyte chemotactic protein-2/cxcl6 by il-1beta and hypoxia in small cell lung cancer. Br J Cancer 2006;94:1936-1941.

-31 Hatfield KJ, Bedringsaas SL, Ryningen A, Gjertsen BT, Bruserud O: Hypoxia increases hif-1alpha expression and constitutive cytokine release by primary human acute myeloid leukaemia cells. Eur Cytokine Netw 2010;21:154-164.

32 Gijsbers K, Gouwy M, Struyf S, Wuyts A, Proost P, Opdenakker G, Penninckx F, Ectors N, Geboes K, Van Damme J: Gcp-2/cxcl6 synergizes with other endothelial cell-derived chemokines in neutrophil mobilization and is associated with angiogenesis in gastrointestinal tumors. Exp Cell Res2005;303:331342.

-33 Karagiannis GS, Saraon P, Jarvi KA, Diamandis EP: Proteomic signatures of angiogenesis in androgenindependent prostate cancer. The Prostate 2014;74:260-272.

34 Raman D, Baugher PJ, Thu YM, Richmond A: Role of chemokines in tumor growth. Cancer Let 2007;256:137-165.

-35 Van Lint P, Libert C: Chemokine and cytokine processing by matrix metalloproteinases and its effect on leukocyte migration and inflammation. J Leukoc Biol 2007;82:1375-1381.

-36 Vandercappellen J, Van Damme J, Struyf S: The role of cxc chemokines and their receptors in cancer. Cancer Let 2008;267:226-244.

37 Zhou SL, Dai Z, Zhou ZJ, Wang XY, Yang GH, Wang Z, Huang XW, Fan J, Zhou J: Overexpression of cxcl5 mediates neutrophil infiltration and indicates poor prognosis for hepatocellular carcinoma. Hepatology 2012;56:2242-2254. 